\title{
Adhesivos autograbantes. ¿Grabar o no grabar?
}

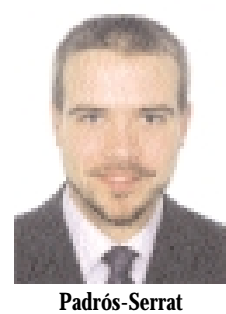

José Luis

\section{Self- etching adhesives. To etch or not to etch?}

\section{Padrós-Serrat, J osé Luis* Monterrubio-Berga, Margarita** Padrós-Cruz, Esteban**}

\author{
*Doctor en Odontología. \\ **Odontólogo. \\ Práctica privada en Barcelona.
}

\begin{abstract}
Resumen: Introducción: en el presente estudio se pretende averiguar si podemos aumentar la fuerza de unión a esmalte y a dentina de los adhesivos autograbantes, introduciendo variaciones en la técnica de uso habitual encaminadas a mejorar sus puntos débiles. Es decir, la permanencia de barrillo dentinario, detritus y gérmenes en la cavidad y la teórica debilidad de su unión al esmalte. Material y método: utilizamos el método de los duelos adhesivos con el fin de saber si un grabado total de la cavidad, o bien un grabado seguido de un lavado con hipoclorito, previos a la aplicación del adhesivo autograbante, aumentarían su eficacia. En la primera parte, dividimos el 1/3 coronario de 120 molares humanos para confrontar las distintas técnicas entre si sobre esmalte en grupos de 10. En la segunda parte dividimos 120 dientes unirradiculares transversalmente unos $2,5 \mathrm{~mm}$ por debajo del nivel del esmalte para confrontar los diferentes métodos ensayados sobre la dentina. En la tercera parte tomamos 36 dientes unirradiculares humanos y les tallamos cavidades cervicales por vestibular y por lingual. Los sometimos a tinción con violeta de genciana para valorar la capacidad de filtración marginal. Resultados: las dos modificaciones propuestas mejoran el resultado obtenido tanto en el esmalte como en la dentina, pero sólo significativamente para Prompt-LPop y One Step Plus. Las pruebas de filtración acusan permeabilidad del colorante en el esmalte cuando no se graba antes de utilizar el adhesivo, lo que parece recomendar su grabado rutinario.
\end{abstract}

Palabras clave: Adhesivo, Autograbante, Filtración, Esmalte, Dentina, Capa híbrida, Fuerza de adhesión, Hipoclorito, Tinción.

Abstract: Introduction: In the present study we try to analyse if we can improve the bond strength and seal of selfetching adhesives to enamel and dentin, by etching with phosphoric acid for 15 seconds or etching followed by deproteinization with sodium hypochlorite $5 \%$ for 30 seconds. Material and method: The duel technique is used to compare the different techniques one by one against the others. In the first part the coronal 1/3 of 120 human molars is cut to test bond strength to enamel. A different technique is used on each side and both parts are bonded with composite resin. By pulling with an Instron machine, we were able to compare which system is stronger in groups of 10 . In the second part, 120 human teeth are horizontally cut $2,5 \mathrm{~mm}$ apical to the enamel margin to test bond strength to dentin. Again a different technique is applied to each side and both sides are bonded with composite resin. In the third part we take 36 human teeth and cervical cavities are prepared in buccal and lingual sides and the teeth are submerged in dye to evaluate leakage. The bonding systems tested were Clearfil SE Bond, Xeno III, One Step Plus + Tyrian SPE and Prompt-LPop. Results: Etching with phosphoric acid or etching followed by sodium hypochlorite rinse improve bond strength in enamel and dentin but only significatively for Prompt-LPop and One Step Plus. Leakage tests reveal permeability in enamel margins for all self-etching adhesives tested that was not present when cavity was etched, wich seems to indicate that etching of enamel margins when using self-etching bonding systems might be useful. There were no differences between etching or etching followed by sodium hypochlorite rinse before applying the adhesive.

Key words: Bond, Self-etch, Leakage, Enamel, Dentin, Hybrid layer, Bond strength, Hypochlorite, Dye.

\begin{tabular}{ccc}
\hline Fecha recepción & Fecha última revisión & Fecha aceptación \\
$9-01-2003$ & $2-06-2003$ & $20-06-2003$ \\
\hline
\end{tabular}

BIBUD [1138-123X (2003)8:4; julio-agosto 349-468]

Padrós-Serrat J L, Monterrubio-Berga M, Padrós-Cruz, E. Adhesivos autograbantes. ¿Grabar o no grabar?. RCOE 2003;8(4):363-375.
J osé Luis Padrós

Muntaner, 373

08021 Barcelona

E-mail: dental@padros. info 


\section{Introducción}

La odontología conservadora no ha dejado de avanzar desde sus primeros pasos. Lejanas quedan ya las inverosímiles e improcedentes prácticas de principio del pasado milenio, dictadas por la más obscura magia y el más sabroso costumbrismo. En aquel entonces y con la mayor solemnidad, se empleaban como material de obturación los excrementos frescos de murciélago, los gusanitos de los cardos bataneros, o incluso un trozo de madera que procediera de un árbol herido por un rayo, a condición, claro está, de que al arrancarlo se tuvieran ambas manos atadas detrás de la espalda ${ }^{1}$. Nuestros ancestros en la profesión, ya entonces, se veían sometidos a pruebas terribles.

Y con la misma sonrisa de indulgente condescendencia con que acaban de leer ustedes los remedios de antaño, no hace mucho leíamos que grabar con ácidos la superficie de la dentina era una maniobra aconsejable. Finalmente rendidos a esta evidencia, y seducidos por la necesidad de eliminar la capa de barrillo dentinario, aparecieron los nuevos adhesivos autograbantes. Realmente, nuestra disciplina pulveriza las sesudas consideraciones Darvinianas sobre la lentitud y parsimonia de la evolución.

La verdad es que las continuas variaciones en las técnicas de uso de los adhesivos que se aplican tras el grabado total de la cavidad, estresan la vida al clínico general.

Para empezar, cuesta dejar que el ácido actúe el tiempo justo. Y resulta que el esmalte requiere mayores tiempos de exposición que la denti$n a^{2,3}$. Una vez hemos grabado y lavado

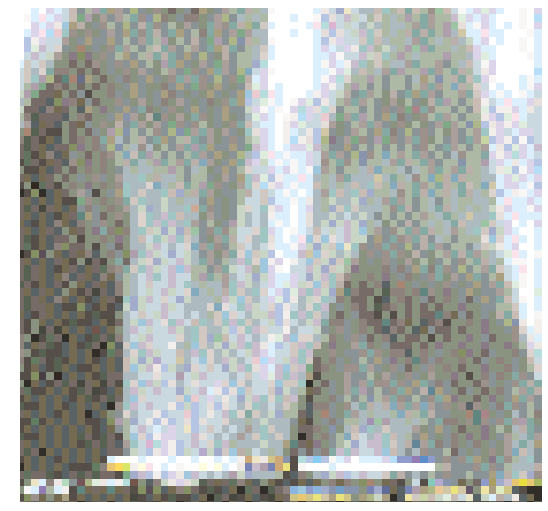

Figura 1. Cuando se aplica un adhesivo sobre una superficie dentinaria excesivamente húmeda pueden formarse glóbulos en los tags de resina. Esta imagen de ESEM (microscopio electrónico de barrido ambiental) muestra tags perfectamente conformados, que rellenan incluso canales intertubulillares junto a otro lleno de glóbulos ilustrando lo dificil que puede resultar controlar perfectamente el grado de humedad superficial al emplear técnicas de unión en húmedo (wet bonding)

en difícil equilibrio entre el cronómetro y la compensación estimativa, se presenta el problema del secado. Si desecamos la cavidad corremos el riesgo de provocar la aspiración de los púdicos odontoblastos hacia el interior de los túbulos y causar un cuadro de sensibilidad postoperatoria**. Además, los adhesivos disueltos en solventes volátiles, como el etanol y especialmente la acetona, deben aplicarse sobre una superficie húmeda para conseguir los mejores resultados $^{5,6}$. Ah, pero ¿cuán húmeda debe quedar? ¿Mojada? ¿Brillante? ¿Perlada?. Un exceso de humedad puede contribuir a la formación de glóbulos en el interior del adhesivo y a crear patrones de adhesión defectuosos ${ }^{7}$ (fig.1). En resumen, completar con éxito una obturación parece requerir más la inspirada creatividad de un chef, improvisando con difíciles ingredientes, que la estricta fidelidad a un método predecible y científico.

Los sistemas de adhesión, contradiciendo otra vez a Darwin, evolucionaron en principio hacia la simplificación, reduciendo el número de frascos y aplicando el adhesivo de una sola vez tras el grabado ácido. No obstante, a pesar de reducir los pasos a seguir, los adhesivos llamados, con poca fortuna literaria, «de un solo frasco», no solucionaban los problemas clínicos mencionados.

Así que la reciente aparición de unos nuevos sistemas adhesivos que con pocos pasos clínicos mantienen altas fuerzas de adhesión y consiguen una incidencia extraordinariamente baja de casos de sensibilidad postoperatoria ${ }^{8}$, ha sido acogida con los brazos abiertos por el clínico práctico, tentado últimamente por volver a recolectar gusanitos en los cardos bataneros.

Los adhesivos autograbantes se aplican directamente sobre la cavidad tallada y seca. Puesto que la superficie dental está recubierta de barrillo dentinario, el secado de la cavidad no producirá el efecto de aspiración odontoblástica, y no hay duda sobre el grado de humedad que requiere cada marca concreta. Su acidez produce la disolución del smear, la descalcificación de la capa más superficial de la dentina y la imprimación de las fibras de colágeno en un único y glorioso paso. Es por eso que resulta teóricamente imposible que quede alguna zona de dentina descalcificada y no impregnada de resina, lo cual constituye un punto débil en la adhesión de los anteriores sistemas de gra- 
bado total ${ }^{9}$. El ph se neutraliza tras el fraguado.

Estos sistemas han demostrado ya conseguir excelentes sellados marginales ${ }^{10}$, y fuerzas de unión a la dentina comparables e incluso superiores a las obtenidas con los anteriores sistemas adhesivos $^{11}$.

Por añadidura alcanzan fuerzas de adhesión estables en el tiempo ${ }^{12 * *}$, que no se ven afectadas por la diferente orientación de los túbulos dentinarios en las distintas superficies cavitarias ${ }^{13}$.

Otra ventaja atractiva para aquellos clínicos que no empleen rutinariamente el dique de goma como método de aislamiento, es que los adhesivos autograbantes no requieren lavado, lo cual evita tener que cambiar los rollos de algodón, reduciendo así el riesgo de contaminar la cavidad.

Es por todo ello por lo que prácticamente todas las casas comerciales han desarrollado y puesto a la venta sus propuestas en adhesión autograbante.

Sin embargo, no todo son ventajas. Al no realizar el paso de grabado y lavado, los nuevos sistemas dejan disuelto en el adhesivo todo el barrillo dentinario que reposaba sobre la cavidad tallada, junto con sus detritus y bacterias, si las contenía. Aunque este hecho no parece constituir ningún problema clínico, nuestros pulcros espíritus antibacterianos se sienten incómodos y conturbados.

Además, con reiterada frecuencia se ha puesto en duda la capacidad de los adhesivos autograbantes de producir un buen patrón de adhesión sobre los prismas de la superficie del esmalte $^{14}$. Algunos autores afirman que la fuerza de adhesión de algunos adhesivos autograbantes es incluso mayor sobre la dentina que sobre el

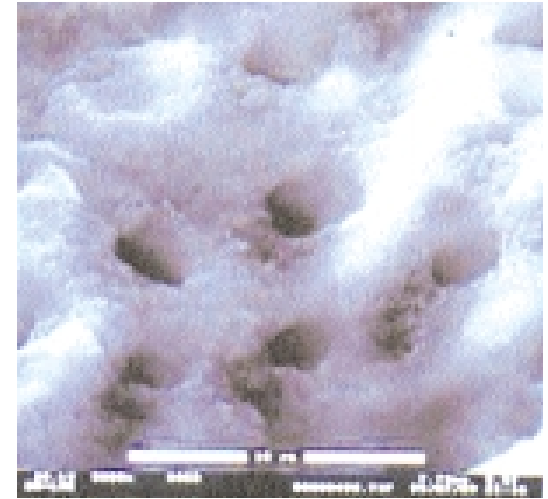

Figura 2. La capa de colágeno desmineralizado que queda en la superficie de la dentina grabada dificulta el contacto directo de la resina con la superficie calcificada de la dentina.

esmalte $^{15}$, y que no alcanza, en este último, la eficacia de sus predecesores, basados en el grabado ácido previo $^{16}$. Este fenómeno parece ocurrir así tanto en el esmalte de dientes permanentes como en el de los deciduos. $Y$ esto es un fastidio, porque, si bien el sellado adecuado y la correcta unión a dentina es esencial, también lo es la unión a esmalte, superficie que se encuentra en el margen de la restauración. Un fallo en este nivel puede favorecer la filtración marginal, y por lo tanto problemas estéticos y ominosos riesgos de caries secundarias. Para evitar este inconveniente, se ha propuesto el uso del grabado ácido sobre el esmalte, antes de emplear un adhesivo autograbante. Eso es algo que parece tener mucho sentido, pues aunque las casas comerciales tienden a elaborar primers autograbantes cada vez más ácidos, el grabado previo del esmalte le proporcionará ese punto extra que requiere en relación a la dentina. Y como chefs de la moderna cocina de la operatoria dental, sentiremos satisfecha nuestra tentación de

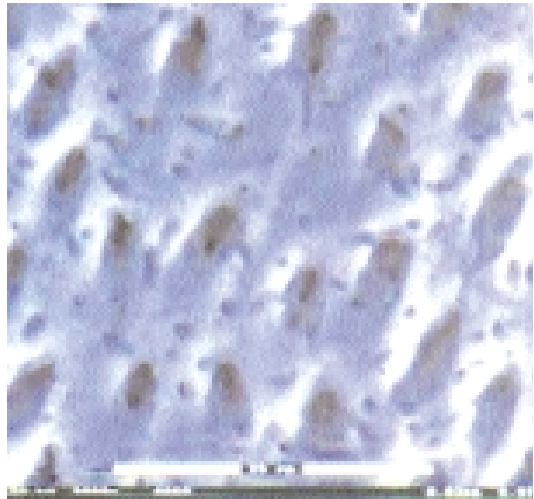

Figura 3. Tras la aplicación del hipoclorito sódico desaparece el colágeno dejando al descubierto multitud de canalillos intertubulares.

añadir pequeños toques e ingredientes que mejoren el resultado final.

Sin embargo, puede resultar clínicamente complejo conseguir el grabado del esmalte sin tocar la dentina. Y... ¿qué ocurre si grabamos la dentina? Pues que volvemos a tener una capa superficial desmineralizada y rica en colágeno que puede ser difícil de impregnar en su totalidad con el monómero adhesivo, exactamente igual que nos ocurría con los adhesivos de grabado total.

Yendo un paso más allá, se propuso hace unos años emplear una técnica de grabado total con ácido ortofosfórico seguido de la eliminación de la capa de colágeno superficial mediante la aplicación de hipoclorito sódico al 2,5-5\%durante 30-60 seg.

Esta técnica se propuso para los adhesivos clásicos de grabado total y pretendía eliminar el barrillo dentinario y a la vez favorecer el contacto directo entre adhesivo y superficie calcificada dentinaria sin el «estorbo» de la capa de fibras de colágeno sin soporte (figs. 2 y 3 ). 


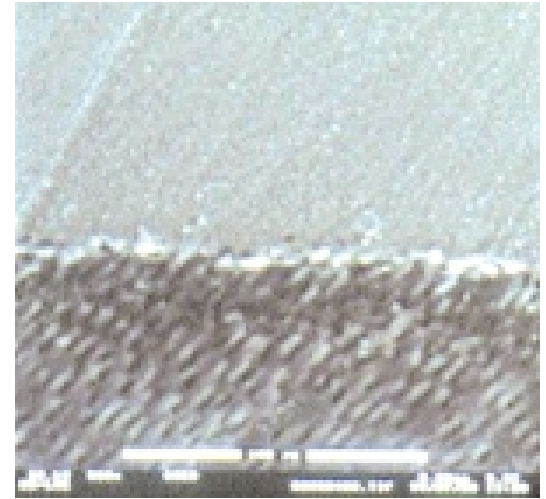

Figura 4. Tras la aplicación de grabado ácido y la desproteinización con hipoclorito la aplicación de un adhesivo hidrofilico (no autograbante) formará uniones adhesivas bien selladas pero al no existir colágeno desmineralizado no se formará capa híbrida.

Siguiendo esos pasos se observan patrones de adhesión muy buenos sin presencia de capa híbrida (fig. 4) y superiores fuerzas de adhesión inmediatas, a la vez que se aprecia un gran entramado de tags de resina que penetran incluso por la multitud de canales intertubulares que aparecen tras la desproteinización con hipoclorito ${ }^{17}$ (figs. 5 y 6).

Sin embargo, Uno y Finger ${ }^{18^{* *}}$ descubrieron que estos patrones de adhesión no eran estables en el tiempo, a diferencia de las uniones que disponen de capa híbrida. Los autores lo atribuyen a la habilidad de dicha capa para absorber fuerzas. Es decir, sin capa híbrida se consiguen uniones más fuertes, pero más rígidas y por tanto menos duraderas. $Y$ eso es una decepción científica. Sin embargo, ¿qué ocurriría si a la superficie grabada con ácido y desproteinizada con hipoclorito le aplicásemos un adhesivo autograbante? Pues que habríamos eliminado el barrillo dentinario,
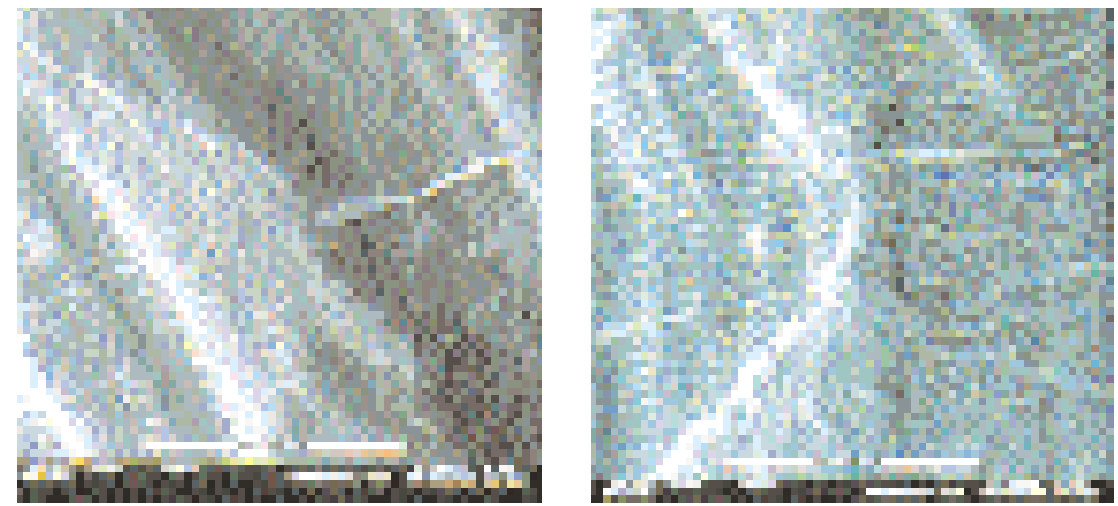

Figuras 5 y 6. El aspecto de los tags de resina formados en una cavidad grabada y desproteinizada con hipoclorito ofrece un aspecto aparentemente mucho más retentivo que cuando no se aplica el hipoclorito. La fig. 5 (izquierda) muestra el aspecto de la resina aplicada en la interfase entre esmalte (derecha) y dentina (izquierda) bajo la cúspide mesial de un molar tras aplicar grabado, adhesivo y composite y la fig. 6 (derecha) el aspecto de la resina aplicada en la interfase entre esmalte y dentina bajo la cúspide distal del mismo molar pero lavando con hipoclorito sódico tras el grabado.

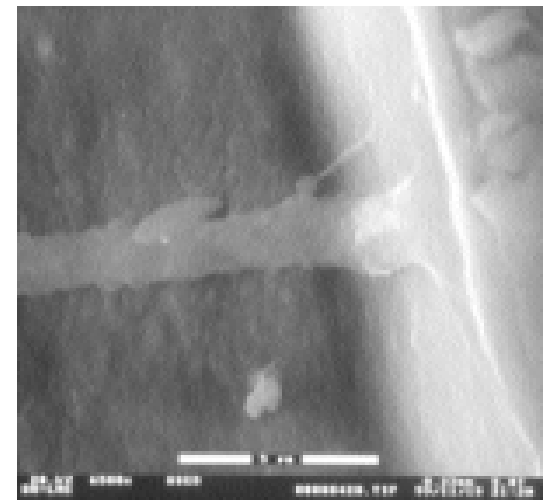

Figura 7. Si tras el grabado y la eliminación del colágeno descalcificado con hipoclorito aplicamos un adhesivo autograbante se formará una nueva capa hibrida gracias a la acidez del imprimador (primer). En la imagen Clearfil SE Bond.

habríamos desinfectado la superficie cavitaria, habríamos grabado el esmalte con un patrón adecuado y a la vez observaríamos la formación de una nueva capa híbrida gracias al efecto ácido del primer, sin el riesgo de dejar una línea de colágeno desmi- neralizado no impregnado como ocurría con los adhesivos anteriores de grabado total (fig. 7).

Esta teoría, tan bella sobre el papel, representa no obstante un desalentador alargamiento del tiempo de aplicación clínica, así que sólo tendría validez si podemos constatar que constituye realmente una mejora.

A fin de comprobar las diferencias entre las tres técnicas, es decir: aplicar un sistema autograbante directamente, hacerlo tras un grabado con ácido ortofosfórico o bien tras el grabado y subsiguiente desproteinización con hipoclorito, decidimos llevar a cabo el presente estudio.

\section{Los duelos de la adhesión}

Generalmente, las pruebas que valoran la fuerza de adhesión emplean métodos de tracción, de cizalla o de flexión en tres puntos sobre dientes diferentes para cada material o técnica evaluado. Calculando las me-dias de resultados se obtiene un valor, 


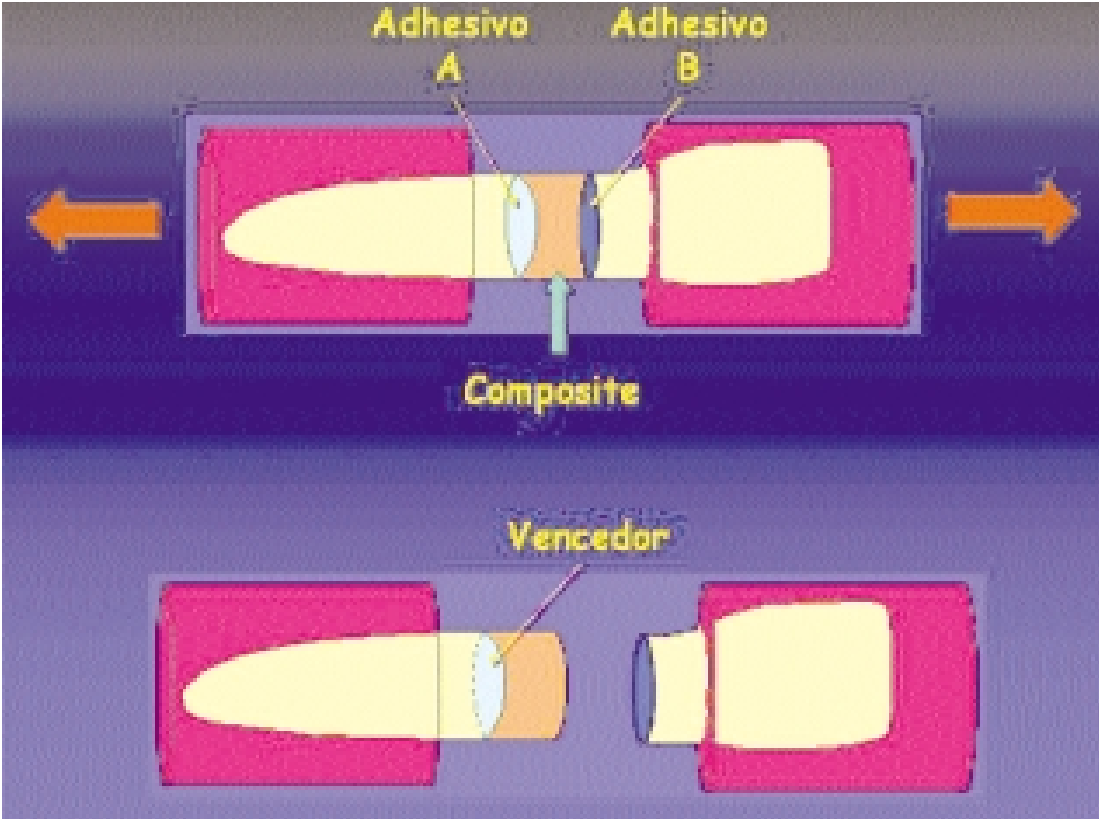

Figura 8. Duelo de adhesión entre dos técnicas diferentes de adhesión sobre un mismo diente.

generalmente expresado en megapascales (MPa) que sirve para comparar unos y otros. Sin embargo, eso se traduce habitualmente en grandes desviaciones estándar y variaciones sorprendentes de resultados entre estudios. Así, por ejemplo, Perdigao y cols $^{19}$ encontraron valores de fuerza de adhesión para Prime $\&$ Bond 2.1 en la dentina de entre 6,6 y 13,9 Mpa, mientras que el Kalla y García Godoy ${ }^{20}$ lo cifraron entre 27,8 y 35,8 . Para Sano y cols $^{12^{2 *}}$ el Clearfil Liner Bond 2 se une a la dentina con una fuerza estable en el tiempo de $19 \mathrm{MPa}$, mientras que para Tanumiharja y cols $^{21}$, ésta oscila entre los 27,9 y los 44,1 $\mathrm{MPa}$. Pioch y cols $^{22}$ cifran la fuerza de unión de Prime $\&$ Bond NT en unos $14,8 \mathrm{MPa}$, que se reduce a unos 8,7 cuando se ensaya con presión pulpar simulada, mientras que Nunes, Swift y Perdigao $^{23}$ lo valoran en $48,2 \mathrm{MPa}$ y Cardoso y cols $^{24}$ en $62 \pm 17,6 \mathrm{MPa}$.
Y eso es así porque dos dientes distintos tienen diferente composición, número de túbulos y edad, el método y tiempo durante el que han sido conservados puede variar, etc. Todo ello brinda sustratos muy heterogéneos sobre los que probar las mismas técnicas y adhesivos.

Para evitar este problema, desarrollamos en 1995 los «apasionantes duelos de la adhesión». Consisten en enfrentar uno a uno entre sí los diferentes materiales y técnicas que queramos valorar sobre dos superficies prácticamente idénticas del mismo diente (fig. 8).

Estos desafíos, que ni siquiera es necesario realizar al amanecer, nos permiten comparar la adhesión al metal, a la dentina, al esmalte o a cualquier superficie que queramos, siempre que las superficies a uno y otro lado del duelo sean lo más exactas que sea posible. Ante todo, «fair play».

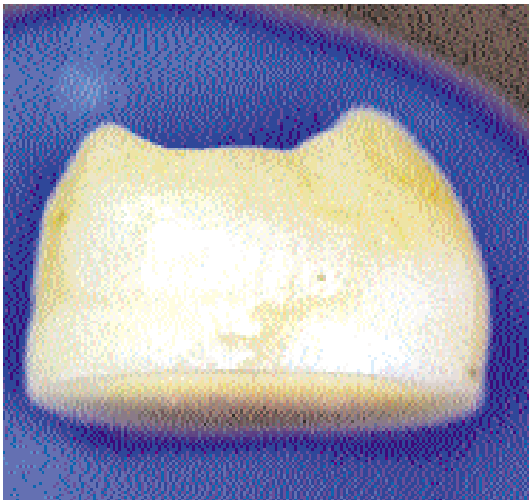

Figura 9. Para las pruebas de fuerza de unión a esmalte se corta horizontalmente a nivel del 1/3 coronal de cada molar

En este estudio, emplearemos los duelos de la adhesión para comparar la fuerza de unión de distintos tipos de adhesivos autograbantes, aplicados, con las tres técnicas ensayadas, tanto en el esmalte como en la dentina. Es más, pretendemos valorar la capacidad de sellado marginal de cada procedimiento.

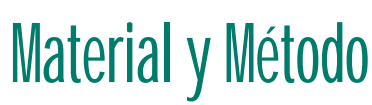

Dividimos el estudio comparativo en tres partes:

\section{1a Parte: Fuerza de unión a esmalte}

Tomamos 120 molares humanos con la corona en buen estado de conservación. Las cortamos horizontalmente a nivel del tercio más coronal con un disco fino de diamante refrigerado con agua, dejando prácticamente sólo el esmalte (fig. 9).

A continuación incluimos cada fragmento en un bloque de resina acrílica con la ayuda de un molde rectangular 


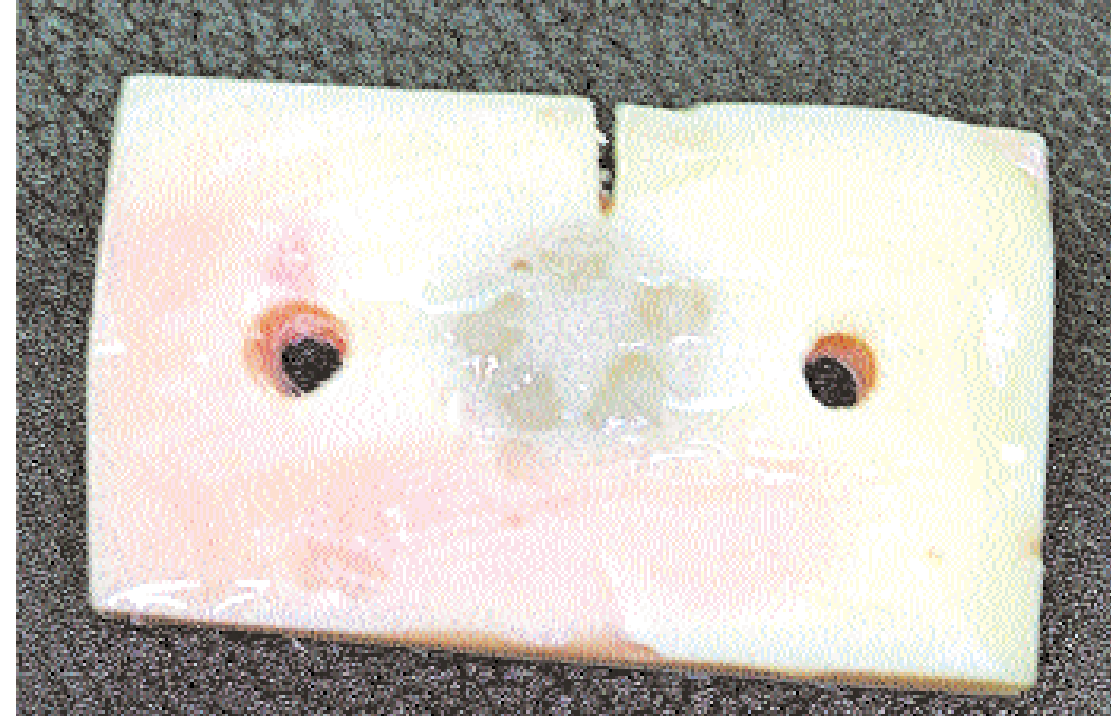

Figura 10. Una vez incluidos los tercios coronarios en los bloques de resina se cortan con un disco fino de diamante dejando dos mitades casi idénticas.

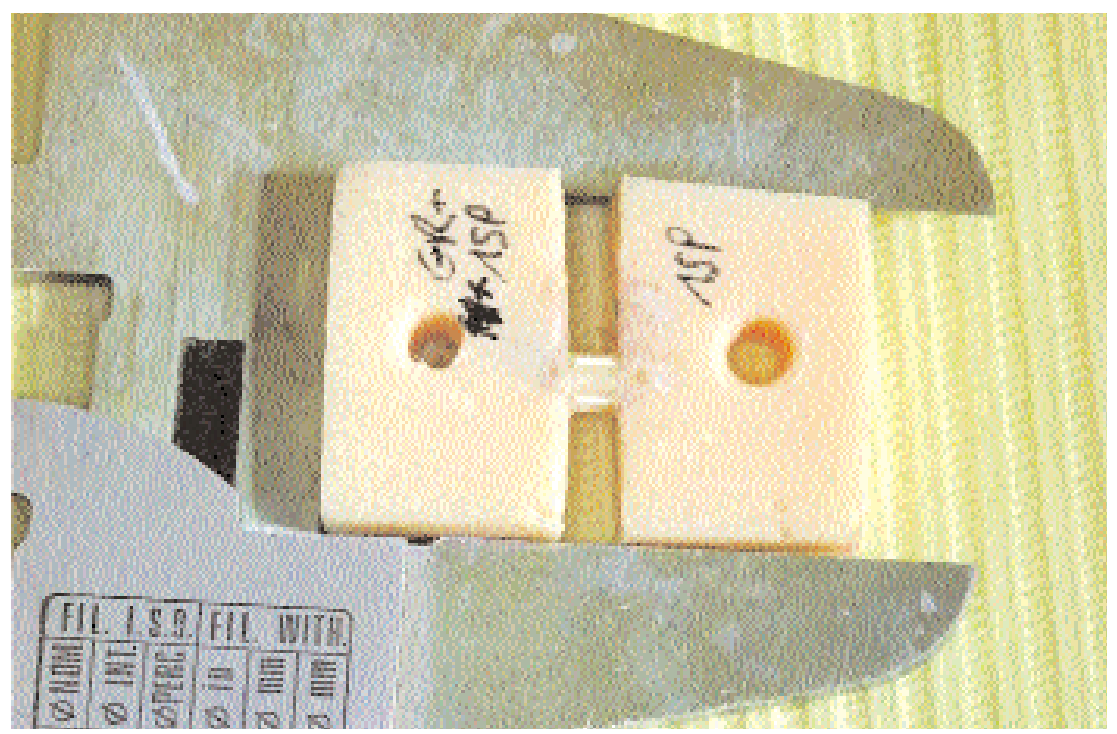

Figura 11. Se alinean los bloques con la ayuda de un pie de rey.

preformado. Una vez fraguada la resina la extraemos del molde y le realizamos dos orificios a cada lado, en la línea media, que nos permitirán efectuar la tracción. Acto seguido cortamos cada preparación con un disco fino de diamante refrigerado con agua, dejando dos mitades casi idénticas (fig. 10).
Entonces decidimos, para cada pareja, una técnica adhesiva distinta a cada lado, lo que nos permitirá comparar, enfrentando una a una, los distintos grupos experimentales. Una vez aplicados los adhesivos, los unimos entre sí mediante un bloque de composite (Tetric Ceram, Vivadent) incluido en un cilindro de acetato transparente. Tras alinear ambas partes con la ayuda de un pie de rey (fig. 11), eliminamos el exceso y lo fraguamos durante 60 segundos con una lámpara halógena (3M 5530) desde cada lado.

Siete días más tarde se somete a tracción con una máquina Instron modelo 1011 a una velocidad de cruceta de $1 \mathrm{~mm} / \mathrm{min}$.

Durante todo el proceso se conservaron las muestras en agua destilada.

Los adhesivos empleados fueron Clearfil SE Bond (Kuraray), Xeno III (Dentsply), One Step Plus + Tyrian SPE (Bisco) y Prompt-LPop (3M-ESPE). Cada uno de ellos, aplicado en un extremo según las instrucciones del fabricante, se enfrentó a sí mismo en el otro extremo, pero tras un grabado completo de la superficie con ácido ortofosfórico al 32\% (Uni-etch, Bisco) durante 15 segundos, seguido de lavado y secado con jeringa de aire-agua. En otro grupo se retaron a sí mismos, en un lado tal y como recomienda el fabricante, y en el otro después del grabado ácido y posterior aplicación de hipoclorito sódico al 5\% durante $30 \mathrm{seg}$, seguido de lavado y secado con jeringa de aireagua. Finalmente, en otro grupo confrontamos entre sí las dos técnicas experimentales, es decir, en un lado empleamos cada adhesivo aplicado tras el grabado ácido, y en el otro lado tras el grabado ácido más la desproteinización con hipoclorito sódico. No se desafiaron distintos adhesivos entre sí.

Se realizaron diez preparaciones de cada duelo.

\section{2a Parte: Fuerza de unión a la dentina.}

Repetimos el proceso de la parte primera con 120 dientes unirradiculares humanos enteros colocados en los 


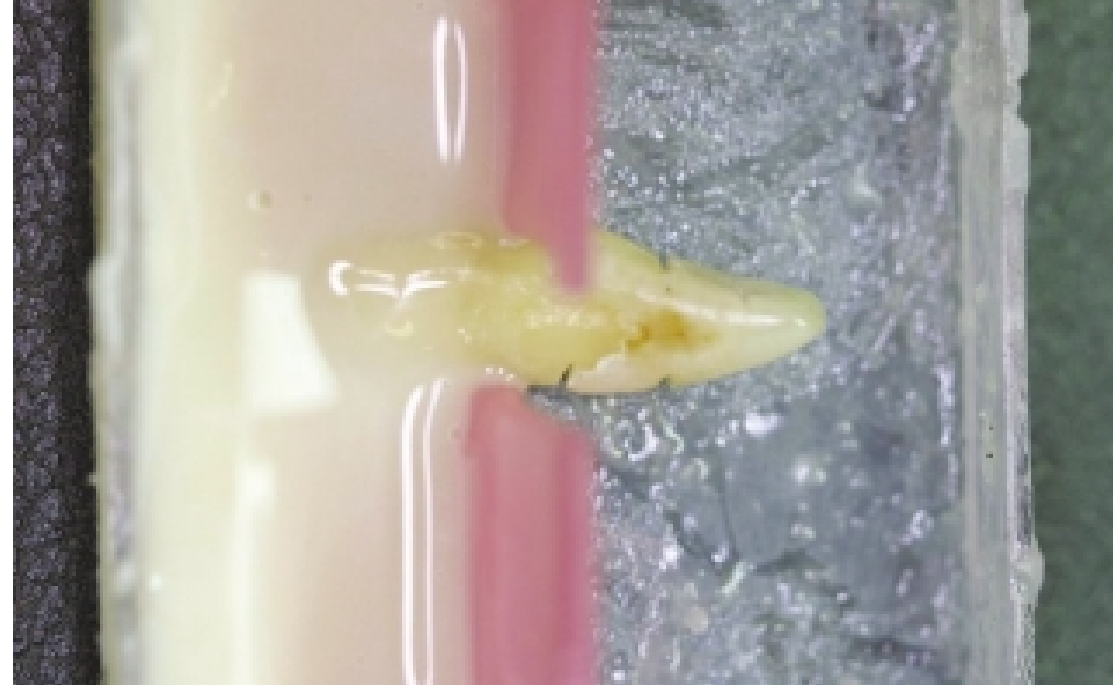

Figura 12. Para las pruebas de fuerza de unión a dentina incluimos dientes unirradiculares en bloques de resina longitudinalmente y no transversalmente como hicimos con las pruebas de unión a esmalte.

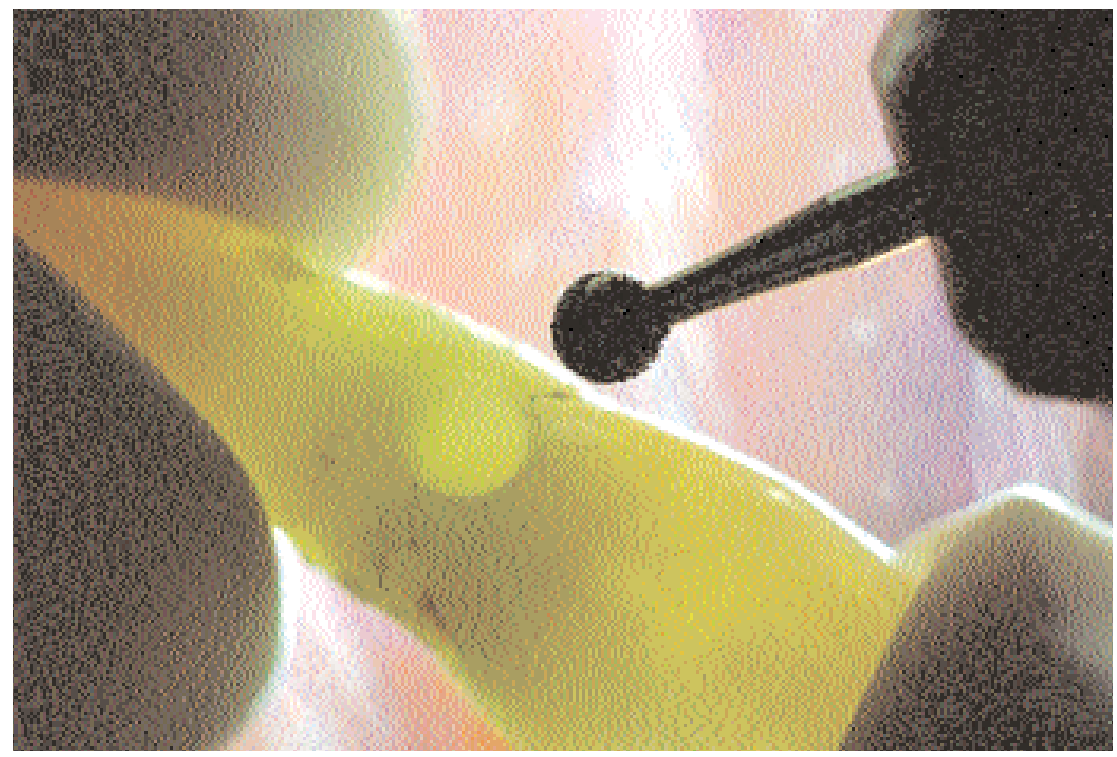

Figura 13. Para las pruebas de filtración marginal preparamos cavidades cervicales en vestibular y palatino con una fresa redonda de diamante refrigerada con agua. El margen coronal se encuentra situado en esmalte y el apical en cemento radicular.

\begin{tabular}{|c|c|c|c|}
\hline \multicolumn{4}{|c|}{ Tabla l' Comparativas de microfilmación } \\
\hline SE--Gr+SE & $\mathrm{X}-\mathrm{-Gr}+\mathrm{X}$ & $\mathrm{P}-\mathrm{G} r+\mathrm{P}$ & $1 S--G r+1 S$ \\
\hline SE--Gr+H+SE & $\mathrm{X}-\mathrm{G}+\mathrm{H}+\mathrm{X}$ & $\mathrm{P}-\mathrm{Gr}+\mathrm{H}+\mathrm{P}$ & $1 S-G r+H+1 S$ \\
\hline $\mathrm{Gr}+\mathrm{SE}-\mathrm{-Gr}+\mathrm{H}+\mathrm{SE}$ & $\mathrm{Gr}+\mathrm{X}-\mathrm{-G}+\mathrm{H}+\mathrm{X}$ & $\mathrm{Gr}+\mathrm{P}-\mathrm{G} r+\mathrm{H}+\mathrm{P}$ & $\mathrm{Gr}+1 \mathrm{~S}-\mathrm{Gr}+\mathrm{H}+1 \mathrm{~S}$ \\
\hline \multicolumn{4}{|c|}{$\begin{array}{l}\text { Leyenda: SE }=\text { Clearfil SE Bond } / / \mathrm{X}=\text { Xeno III // P = Prompt-L-pop // } \\
1 \mathrm{~S}=\text { One Step Plus } / / \mathrm{Gr}=\mathrm{Grabado} \text { ac. ortofosfórico } / / \mathrm{H}=\text { Hipoclorito }\end{array}$} \\
\hline
\end{tabular}

bloques de resina longitudinalmente y no transversalmente como hicimos con las coronas de los molares (fig. 12). Antes de incluirlos en los bloques de resina les realizamos unos cortes en los extremos coronal y apical para aumentar la retención de la resina.

Cortamos los bloques por la dentina radicular a unos $2,5 \mathrm{~mm}$ del nivel del esmalte.

Bloqueamos el orificio del conducto radicular con un material inerte (Cavit ESPE). Aplicamos los adhesivos, alternando las posiciones de cada técnica de preparación entre la mitad coronal y la apical, y después de interponer el bloque de composite procedemos a ser testigos de los duelos. Traccionamos con la máquina instron del mismo modo que hicimos en la primera parte.

Consideramos estadísticamente significativo un resultado de ocho victorias por dos derrotas o superior $(p=0,05)$.

\section{3a Parte: Microfiltración.}

Tomamos 36 dientes unirradiculares humanos y los repartimos aleatoriamente en cuatro grupos. En cada muestra tallamos dos cavidades, una en el lado vestibular y una en el lingual. Empleamos para ello una fresa redonda de diamante para turbina, refrigerada con agua. Las cavidades se tallaron en el cuello del diente, dejando el margen coronal situado en el esmalte y el apical en el cemento radicular (fig. 13).

Hundimos la fresa justo hasta su ecuador, a fin de estandarizar lo máximo posible la forma y tamaño de las cavidades.

Comparamos uno a uno los cuatro adhesivos evaluados en este estudio según las diferentes técnicas de aplicación, tal como se muestra en la tabla 1. 


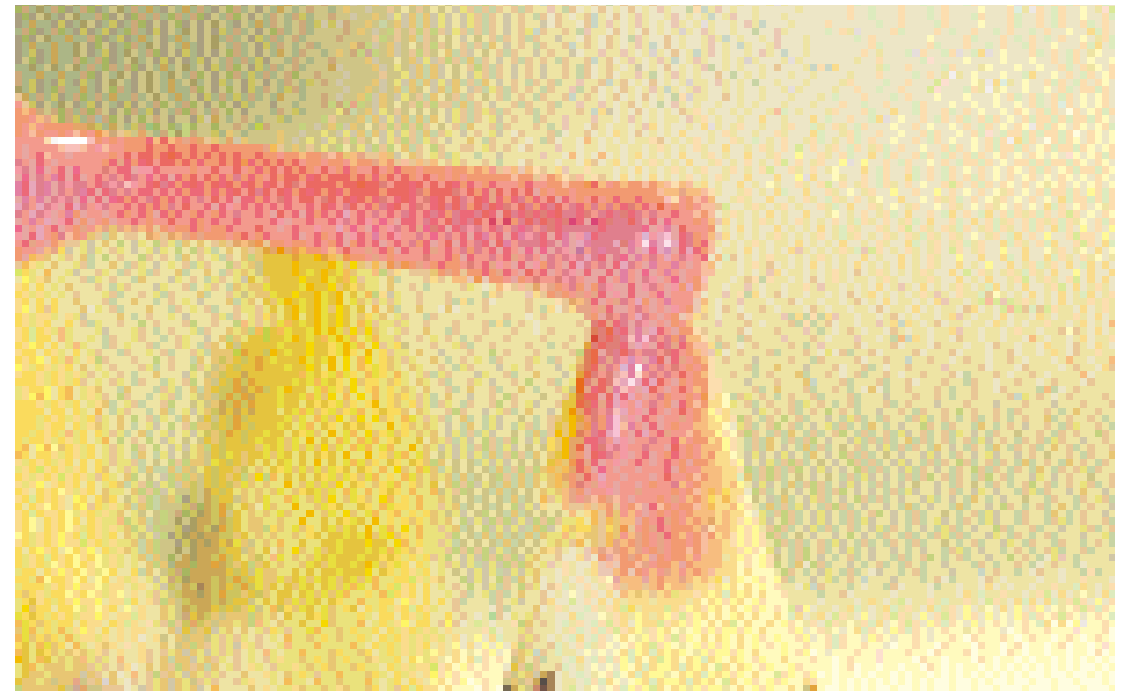

Figura 14. Sellamos las raices con laca de uñas.

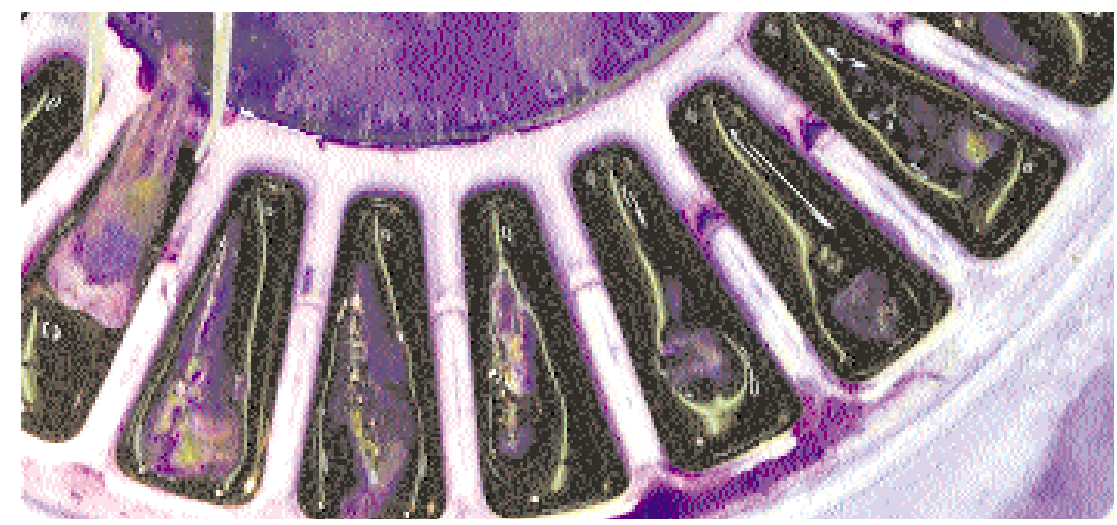

Figura 15. Sumergimos cada diente en una solución de violeta de genciana durante 24 horas.

Una vez preparadas, termociclamos las muestras (200 ciclos de $60 \mathrm{seg}$. entre $\left.4-60^{\circ} \mathrm{C}\right)$, sellamos las raíces con laca de uñas (fig. 14) y sumergimos todas las preparaciones en violeta de genciana durante 24 horas (fig. 15).

A continuación las cortamos con un disco de diamante refrigerado por aire y evaluamos el grado de filtración, bajo estereomicroscopio (Iroscope NZ14T, Mexico), según la escala de la tabla 2.

Cada cavidad se evaluó en el esmalte y en la dentina.

\begin{tabular}{|c|c|}
\hline $\begin{array}{l}\text { Tabla 2: } \\
\text { grado }\end{array}$ & $\begin{array}{l}\text { scala de medición del } \\
\text { filtración marginal }\end{array}$ \\
\hline Grado 0. & $\begin{array}{l}\text { Ausencia total de filtra- } \\
\text { ción marginal. }\end{array}$ \\
\hline Grado 1 & $\begin{array}{l}\text { Filtración marginal de } \\
\text { colorante hasta un máxi- } \\
\text { mo de } 1 \mathrm{~mm} \text {. }\end{array}$ \\
\hline Grado 2 & $\begin{array}{l}\text { Penetración de coloran- } \\
\text { te mayor a 1mm pero } \\
\text { sin llegar al fondo cavita- } \\
\text { rio. }\end{array}$ \\
\hline Grado 3 & $\begin{array}{l}\text { Penetración del coloran- } \\
\text { te hasta el fondo de la } \\
\text { cavidad. }\end{array}$ \\
\hline
\end{tabular}

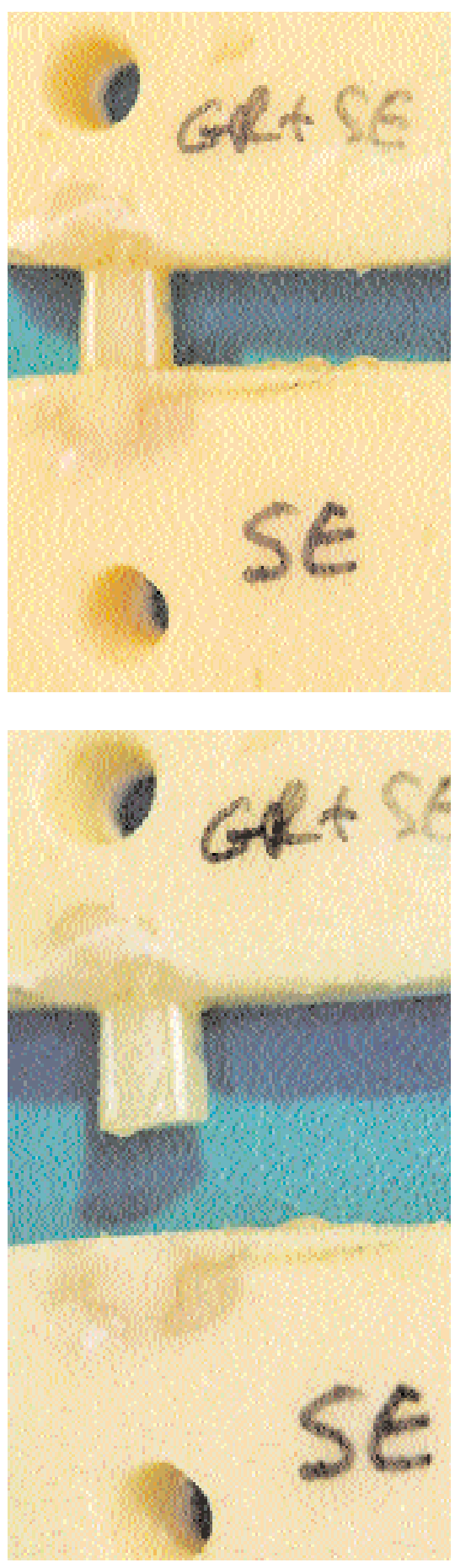

Figuras 16 y 17. Resultado de uno de los duelos sobre esmalte para Clearfil SE Bond. En este caso venció la superficie sobre la que se realizó el grabado previo con ácido ortofosfórico. 


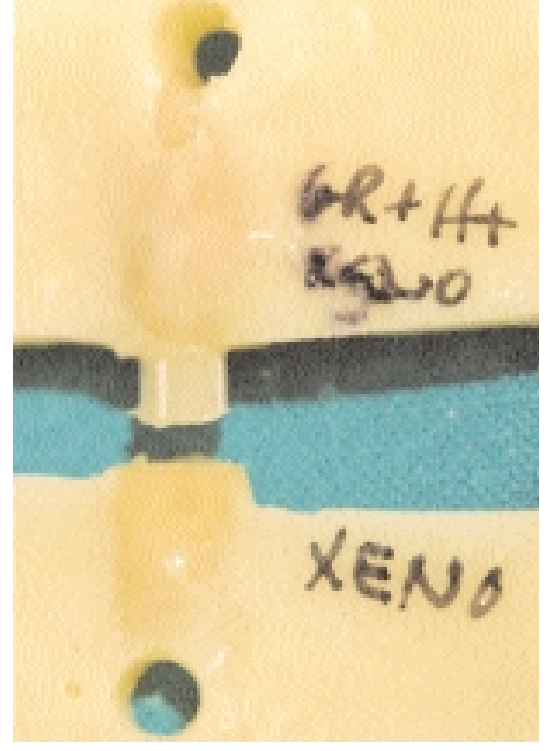

Figura 18. Resultado de un duelo de adhesión a dentina para Xeno III. En este caso, la superficie pretratada con ácido e hipoclorito venció.

\section{Resultados}

En la tabla 3 se muestran los resultados de las pruebas de la fuerza de unión al esmalte, en la tabla 4 los de unión a la

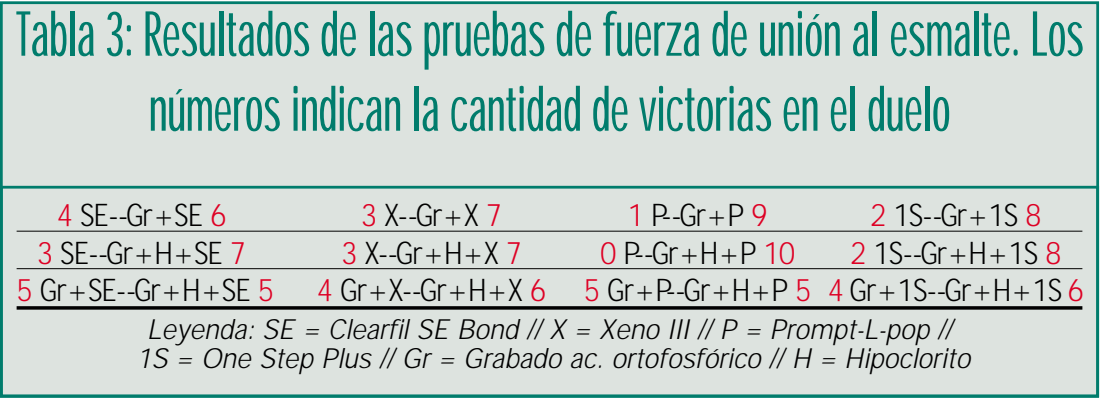

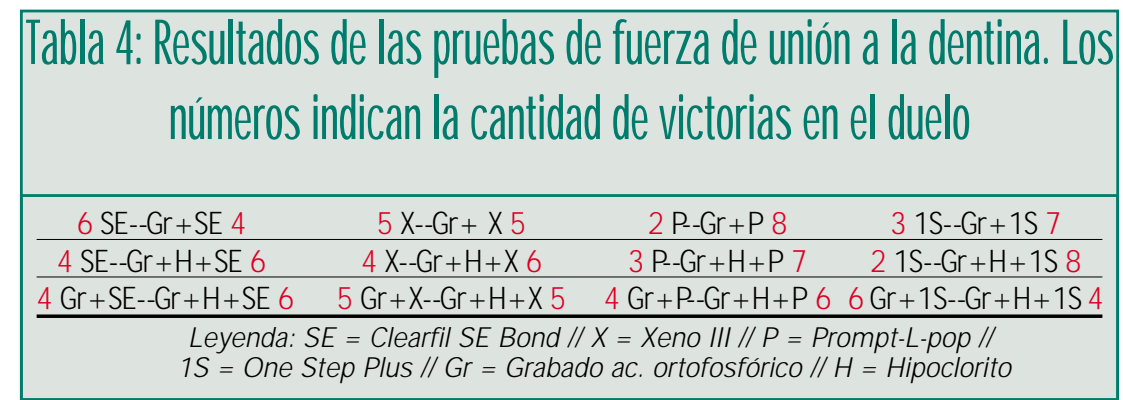

dentina y en las tablas 5 y 6 los de las pruebas de filtración marginal en el esmalte y la dentina respectivamente.

Todas las muestras presentaron fallos adhesivos. El composite no se fracturó (figs. 16-18).

Respecto a las pruebas de filtración marginal, todos los sistemas adhesivos ensayados mostraron filtración marginal, principalmente a lo largo del esmalte. En diversas preparaciones la filtración atravesó el esmalte y se detuvo justamente al comenzar la dentina (figs. 19 y 20).

\section{$\mathrm{Gr}+\mathrm{SE}$}
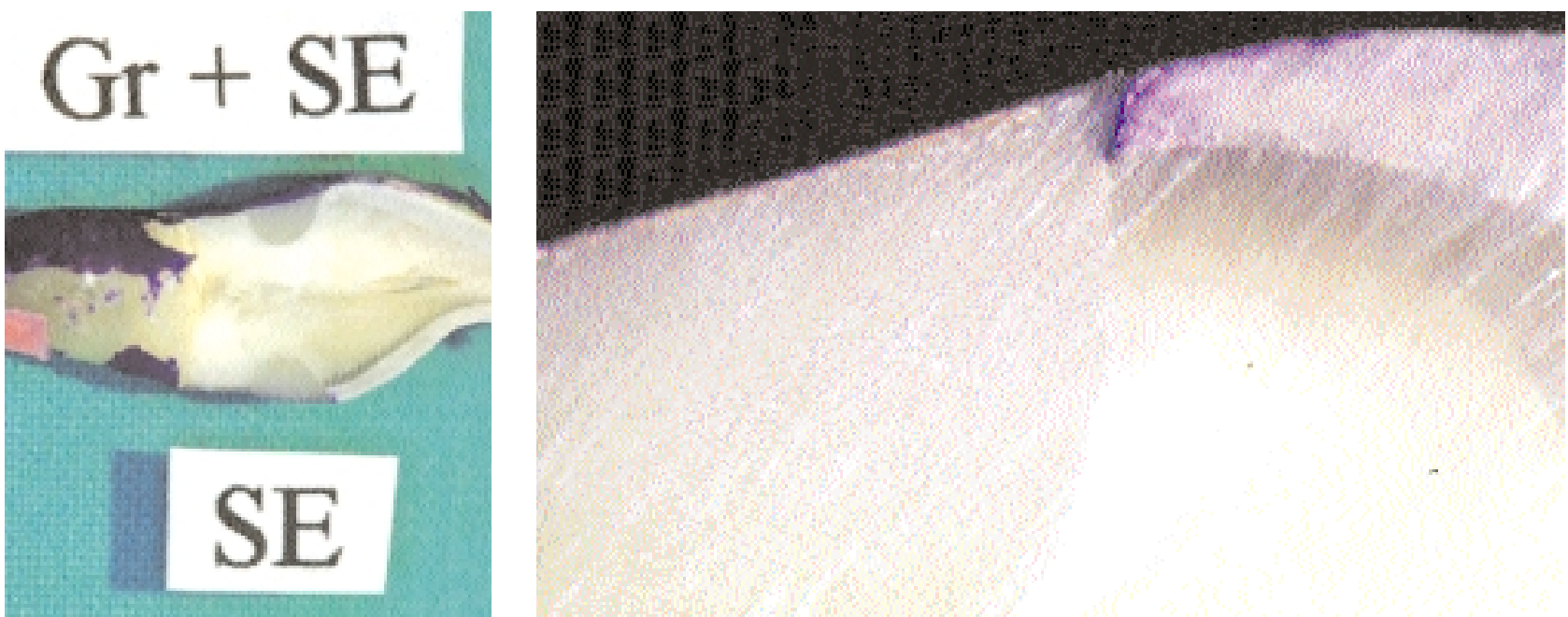

Figuras. 19 y 20. Los adhesivos autograbantes aplicados sin grabado ácido previo presentaron a menudo filtraciones que atravesaban el esmalte y se detenian al llegar a la dentina. La fig. 19 (izquierda) muestra el típico patrón de filtración en el esmalte que se detiene al llegar a la dentina de los adhesivos autograbantes. En este caso se trata de Xeno III. 

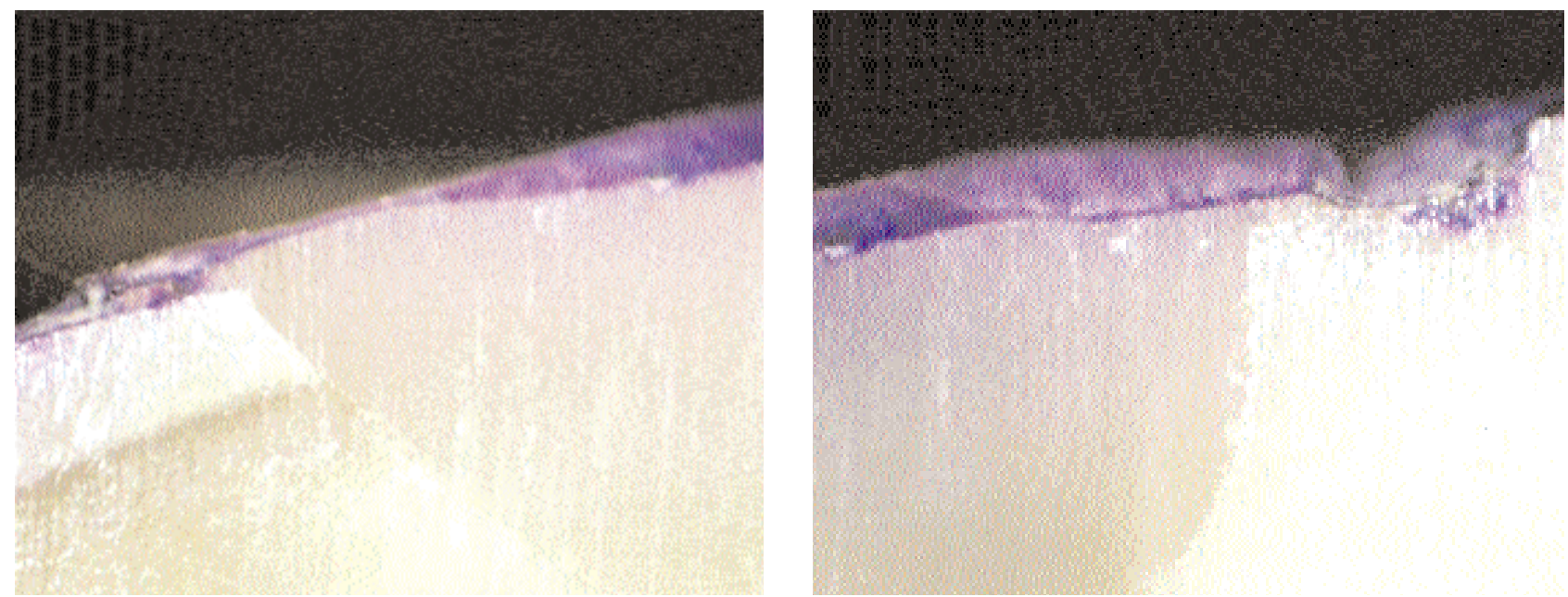

Figuras. 21 y 22. Al aplicar los adhesivos tras el grabado ácido o tras el grabado y la desproteinización con hipoclorito, el problema de la filtración marginal en el esmalte desaparece y se consiguen sellados muy buenos tanto en el esmalte (fig. 21, a la izquierda) como en la dentina (fig. 22, a la derecha).

\section{$\mathrm{Gr}+\mathrm{Xeno}$}

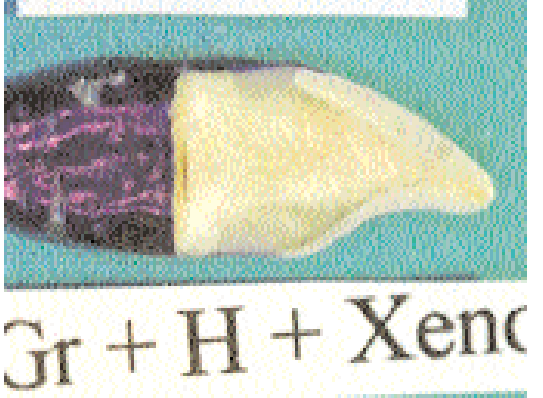

Figura. 23. No existieron diferencias significativas entre la capacidad de sellado de los adhesivos aplicados tras el grabado ácido (arriba) o tras el grabado ácido seguido de hipoclorito (abajo).

Este patrón de filtración desaparecía en los casos en los que se había aplicado previamente un grabado ácido con o sin hipoclorito (figs. 21 y 22 ).

No existieron diferencias significativas entre los resultados obtenidos en las muestras pre-tratadas con gra-

\begin{tabular}{|c|c|c|c|c|}
\hline & GRADO 0 & GRADO 1 & GRADO 2 & GRADO 3 \\
\hline SE & 0 & 3 & 0 & 0 \\
\hline $\mathrm{Gr}+\mathrm{SE}$ & 3 & 0 & 0 & 0 \\
\hline $\mathrm{Gr}+\mathrm{H}+\mathrm{SE}$ & 3 & 0 & 0 & 0 \\
\hline $\mathrm{X}$ & 0 & 2 & 1 & 0 \\
\hline $\mathrm{Gr}+\mathrm{X}$ & 3 & 0 & 0 & 0 \\
\hline $\mathrm{Gr}+\mathrm{H}+\mathrm{X}$ & 3 & 0 & 0 & 0 \\
\hline$P$ & 1 & 1 & 0 & 1 \\
\hline $\mathrm{Gr}+\mathrm{P}$ & 2 & 1 & 0 & 0 \\
\hline $\mathrm{Gr}+\mathrm{H}+\mathrm{P}$ & 3 & 0 & 0 & 0 \\
\hline $1 \mathrm{~S}$ & 1 & 1 & 1 & 0 \\
\hline $\mathrm{Gr}+1 \mathrm{~S}$ & 2 & 1 & 0 & 0 \\
\hline $\mathrm{Gr}+\mathrm{H}+1 \mathrm{~S}$ & 2 & 1 & 0 & 0 \\
\hline
\end{tabular}

bado ácido, con o sin desproteinización con hipoclorito (fig. 23).

\section{Discusión}

La eclosión comercial de los adhesivos autograbantes ha venido a reforzar nuestro armamentarium odontológico en operatoria dental. Aunque su comportamiento clínico a medio y largo plazo está siendo aún evaluado, multitud de estudios avalan ya su eficacia.

Debido a su juventud en el mercado, aún no disponemos de bibliografía acerca de Xeno III ni de One Step Plus que nos permita contrastar nuestros resultados. Sí existen, no obstante, para el Clearfil SE Bond y el Prompt-L Pop, adhesivos más veteranos.

El Clearfil SE Bond es un adhesivo

RCOE, 2003, Vol 8, №4, 363-375 


\begin{tabular}{|c|c|c|c|c|}
\hline & GRADO 0 & GRADO 1 & GRADO 2 & GRADO 3 \\
\hline SE & 1 & 1 & 1 & 0 \\
\hline $\mathrm{Gr}+\mathrm{SE}$ & 3 & 0 & 0 & 0 \\
\hline $\mathrm{Gr}+\mathrm{H}+\mathrm{SE}$ & 3 & 0 & 0 & 0 \\
\hline $\mathrm{X}$ & 2 & 1 & 0 & 0 \\
\hline$G r+X$ & 3 & 0 & 0 & 0 \\
\hline $\mathrm{Gr}+\mathrm{H}+\mathrm{X}$ & 3 & 0 & 0 & 0 \\
\hline $\mathrm{P}$ & 2 & 1 & 0 & 0 \\
\hline$G r+P$ & 3 & 0 & 0 & 0 \\
\hline $\mathrm{Gr}+\mathrm{H}+\mathrm{P}$ & 3 & 0 & 0 & 0 \\
\hline $1 S$ & 2 & 0 & 1 & 0 \\
\hline $\mathrm{Gr}+1 \mathrm{~S}$ & 2 & 1 & 0 & 0 \\
\hline $\mathrm{Gr}+\mathrm{H}+1 \mathrm{~S}$ & 3 & 0 & 0 & 0 \\
\hline
\end{tabular}

que ha sido ya muy estudiado y que presenta resultados muy consistentes $^{25}$. Prompt-LPop, por su lado, demuestra, en general, resultados prometedores en las pruebas de unión a esmalte y no tan buenos a la dentina ${ }^{26}$. Al parecer, la aplicación de varias capas mejora considerablemente sus prestaciones $^{27}$.

Sin embargo, respecto a las pruebas de filtración marginal, y contrariamente a lo hallado en nuestro ensayo, varios estudios encuentran, empleando adhesivos autograbantes, un mayor grado de filtración en los márgenes situados sobre dentina que en aquellos situados sobre el esmalte ${ }^{28,29}$.

No hemos incluido en los resultados los valores de fuerza registrados por la máquina Instron en la desunión de las muestras, puesto que el objetivo del ensayo era comparar directamente dos procedimientos para dilucidar cuál era el que producía la unión más fuerte, y no obtener un valor en MPa que se sume al sorprendentemente veleidoso balance de Mpa de la literatura. Además, dependiendo del lugar donde se produjese la desunión, el valor de fuerza en MPa estaría representado a técnicas distintas.

En este sentido encontramos que, por lo general, la aplicación del grabado ácido o bien del grabado más la desproteinización con hipoclorito, mejora los resultados obtenidos cuando se obedece religiosamente las instrucciones del fabricante. Sin embargo, esta mejora es significativa solamente para Prompt-LPop y One Step Plus, tanto en el esmalte como en la dentina. La adición de hipoclorito tras el grabado, como paso intermedio, no se traduce en una mejora significativa en ningún caso, a pesar de la ventaja teórica que ello representa.

Respecto a las pruebas de filtración marginal, sorprende que cuando los adhesivos autograbantes se emplean con una rigurosa observancia hacia los preceptos del fabricante, muestren un repetitivo patrón de filtración en el esmalte, especialmente para los clínicos acostumbrados a las bondades de dicho esmalte. Un patrón de filtración, además, que se detiene, respetuoso, tímido casi, en cuanto llega a la dentina. Es decir, que todos los adhesivos ensayados, aplicados tal cual, parecen sellar mejor las interfases situadas sobre la dentina que las situadas sobre el esmalte. El cambio radical en la capacidad de sellado cuando los mismos adhesivos se administran tras el grabado ácido o el grabado seguido del hipoclorito, parece recomendar el uso rutinario del grabado ácido sobre el esmalte para mejorar el sellado marginal, especialmente en aquellas situaciones en que el esmalte representa una parte importante de la cavidad.

Este tipo de sistemas adhesivos está diseñado específicamente para su aplicación directa sobre los tejidos duros dentales. Cuando se respetan los protocolos descritos por las casas comerciales, ofrecen fuerzas de unión muy satisfactorias, así como un sellado marginal bastante bueno en la superficie dentinaria, y no tan bueno en el esmalte. A la vista de los resultados observados en este estudio, parece recomendable pre-tratar la cavidad, especialmente el esmalte, con ácido ortofosfórico. Grabar la dentina también mejora los resultados, aunque sólo significativamente para Prompt-LPop y One Step Plus (fig. 24 y 25).

Aplicar el grabado ácido sobre la dentina, sin embargo, elimina la capa de barrillo dentinario y ensancha las aperturas de los tubulillos dentinarios. La administración de hipoclorito tras el grabado elimina la capa de colágeno desmineralizada y evita el riesgo de dejar una capa híbrida incompletamente impregnada, a la vez que ofrece un efecto desinfectante que siempre es de agradecer. Sin embargo, aumenta el riesgo de 

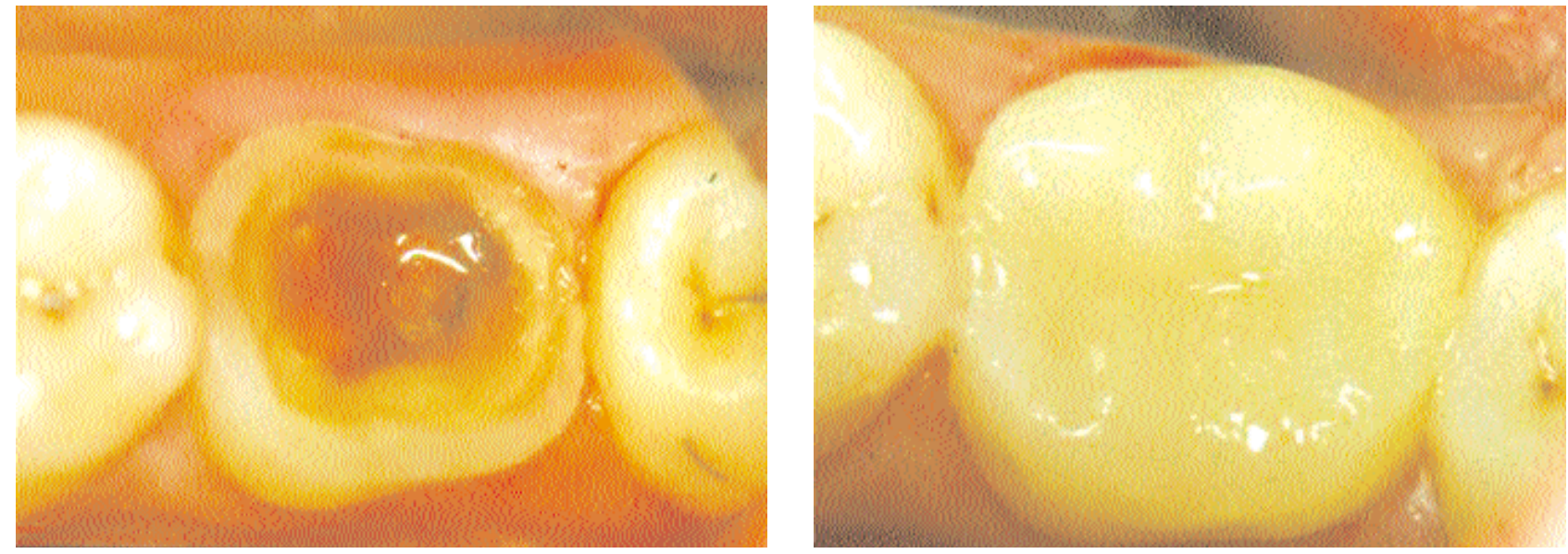

Figuras. 24 y 25. La aplicación de grabado previo al uso de Prompt-L-Pop y One Step Plus aumenta la fuerza de adhesión. El clinico debe ser quien decida en cada caso en función de sus ventajas e inconvenientes.

perturbar la paz tibetana de los odontoblastos, que pueden llegar a ser aspirados hacia el interior de los túbulos dentinarios, elevando el riesgo de producir un cuadro de sensibilidad post-operatoria. El proceso, además, comporta un aumento del número de pasos, y por lo tanto del tiempo de aplicación clínica, lo cual es desalentador para el sufrido profesional. Es decir, que a la vista de los resultados de este estudio, debe ser el clínico el que valore la conveniencia o no de efectuar esta modificación de la técnica para conseguir un mejor sellado marginal y, según el adhesivo, un aumento de la fuerza de unión.

Serán necesarios estudios clínicos que confirmen las ventajas de aplicar in vivo los procedimientos ensayados in vitro.

RCOE, 2003, Vol 8, №4, 363-375

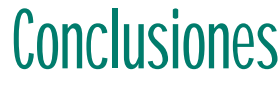

Bajo las condiciones del presente estudio podemos concluir que:

1. El grabado ácido de la cavidad antes de emplear el adhesivo autograbante, con o sin lavado posterior con hipoclorito sódico al $5 \%$ durante 30 seg, aumenta su fuerza de adhesión tanto en el esmalte como en la dentina, pese a que los fabricantes no recomiendan este paso. No obstante, esta mejora sólo es significativa para dos de los productos ensayados en este trabajo: Prompt-t-Pop y One Step Plus.

2. En las pruebas de filtración marginal, hemos comprobado que el empleo del adhesivo en la técnica recomendada por el fabricante conduce a un patrón de filtración en el esmalte que parece corroborar la menor eficacia de estos adhesivos en este nivel. El grabado de la cavidad, seguido o no de un lavado con hipoclorito, nos muestra un patrón mucho más satisfactorio, y un sellado marginal en el esmalte altamente fiable.

3. Por lo tanto, el grabado previo del esmalte, sin que deba perturbarnos su extensión a la dentina, parece una maniobra aconsejable antes de la aplicación de un adhesivo autograbante, ya que la fuerza de adhesión no se ve perjudicada, más bien al contrario, y el sellado marginal en el esmalte mejora substancialmente. Aún así, un grabado de la cavidad exige un lavado y secado que puede originar sensibilidad postoperatoria, y las modificaciones propuestas en este trabajo conllevan mayor tiempo de trabajo. Por lo que el clínico debe valorar en cada caso, la conveniencia o no de incorporarlas a su protocolo. 


\section{Bibliografía recomendada}

Para profundizar en la lectura de este tema, el/los autor/es considera/an interesantes los artículos que aparecen señalados del siguiente modo: * de interés ${ }^{* *}$ de especial interés.

1. Lerman S. Historia de la odontología y su ejercicio legal. Paraguay: Ed. Mundi,1974:25-406.

2. Gardner A, Hobson R. Variations in acid-etch patterns with different acids and etch times. Am $\mathrm{J}$ Orthod Dentofacial Orthop 2001;20(1):64-7.

3. Uno S, Finger WJ. Effects of acidic conditioners on dentine demineralization and dimension of hybrid layers. J Dent 1996;24(3):211-6.

4*. Brannstrom M, Johnson G. The sensory mechanism in human dentin as revealed by evaporation and mechanical removal of dentin. J Dent Res 1978;57(1):49-53.

El movimiento de fluido dentinario producido por su evaporación en los túbulos expuestos de la dentina puede producir dolor y aspiración de los odontoblastos.

5. Gwinnett AJ. Moist versus dry dentin: its effect on shear bond strength. Am J Dent. 1992;5(3):127-9.

6. Pereire GD, Paulillo LA, De Goes MF, Dias CT. How wet should dentin be? Comparison of methods to remove excess water during moist bonding. J Adhes Dent 2001;3(3):257-64.

7*. Tay FR, Gwinnett AJ, Wei SH. The overwet phenomenon: an optical, micromorphological study of surface moisture in the acid-conditioned, resin-dentin interface. Am J Dent 1996;9(1):43-8.

El exceso de humedad en la superficie de la dentina previo a la aplicación de adhesivos hidrofilicos puede producir atrapamiento de agua y creación de glóbulos creando un defectuoso patrón de unión.

8. Swift EJ Jr. Dentin/enamel adhesives: review of the literature. Pediatr Dent 2002;24(5):456-61.

9. Li HP, Burrow MF, Tyas MJ. The effect of longterm storage on nanoleakage. Oper Dent 2001;26(6):609-16.

10. Besnault C, Attal JP. Influence of a simulated oral environment on microleakage of two adhesive systems in Class II composite restorations. J Dent 2002;30(1):1-6.
11. Tanumiharja M, Burrow MF, Tyas MJ. Microtensile bond strengths of seven dentin adhesive systems. Dent Mater 2000;16(3):180-7.

12**. Sano H, Yoshikawa T, Pereira PN, et al. Long-term durability of dentin bonds made with a self-etching primer, in vivo. J Dent Res 1999;78(4):906-11

Las fuerzas de unión obtenidas mediante adhesivos autograbantes permanecieron estables en aproximadamente $19 \mathrm{MPa}$ durante el período de evaluación de 1 año.

13. Phrukkanon S, Burrow MF, Tyas MJ. The effect of dentine location and tubule orientation on the bond strengths between resin and dentine. J Dent 1999;27(4):265-74

14. Glasspoole EA, Erickson RL, Davidson CL. Effect of enamel pretreatments on bond strenght of compomer. Dent Mater 2001;17(5)402-8.

15. Toledano M, Osorio R, de Leonardi G, RosalesLeal JI, Ceballos L, Cabrerizo-Vilchez MA. Influence of self-etching primer on the resin adhesion to enamel and dentin. Am J Dent 2001;14(4):205-10.

16. Hara AT, Amaral CM, Pimenta LA, Sinhoreti MA. Shear bond strength of hydrophilic adhesive systems to enamel. Am J Dent 1999;12(4):181-4.

17. Padrós E, Padrós JL, Manero JM. Los fastidiosos enigmas de la adhesión dentinaria (nuevas reflexiones). Ideas Trabajos Odontoestomatol 2000;1(1):8-37.

$18^{* *}$. Uno S, Finger WJ. Function of the hybrid zone as a stress absorbing layer in resin-dentin bonding. Quintessence Int 1995;26(10):7338.

La capa híbrida de colágeno-polímero creada en la superficie de la dentina con determinados sistemas adhesivos cumple una misión importante compensando el estrés de contracción.

19. Perdigao J, Swift EJ Jr, Heymann HO, Malek MA. Effect of a re-wetting agent on the per- formance of acetone-based dentin adhesives. Am J Dent 1998;11(5):207-13.

20. el Kalla IH, Garcia-Godoy F Bond strength and interfacial micromorphology of four adhesive systems in primary and permanent molars. ASDC J Dent Child 1998;65(3):169-76.

21. Tanumiharja M, Burrow MF, Tyas MJ. Microtensile bond strengths of seven dentin adhesive systems. Dent Mater 2000;16(3):180-7.

22. Pioch T, Staehle HJ, Schneider H, Duschner H, Dorfer CE. Effect of intrapulpal pressure simulation in vitro on shear bond strengths and hybrid layer formation. Am J Dent 2001;14(5):319-23

23. Nunes MF, Swift EJ, Perdigao J. Effects of adhesive composition on microtensile bond strength to human dentin. Am J Dent 2001;14(6):340-3.

24. Cardoso PE, Carrilho MR, Francci CE, Perdigao $\mathrm{J}$. Microtensile bond strengths of one-bottle dentin adhesives. Am J Dent 2001;14(1):22-4

25. Hannig M, Reinhardt KJ, Bott B. Self-etching primer vs. phosphoric acid: an alternative concept for composite-to enamel bonding. Oper Dent 1999;24(3):172-80.

26. Kaaden C, Powers JM, Friedl KH, Schmalz $\mathrm{G}$. Bond strength of self-etching adhesives to dental hard tissues. Clin Oral Investig 2002;6(3):155-60

27. Frankenberger R, Perdigao J, Rosa BT, Lopes M «No-bottle» vs «multi-bottle» dentin adhesives. A microtensile bond strength and morphological study. Dent Mater 2001;17(5):373-80.

28. Santini A, Plasschaert AJ, Mitchell S. Effect of composite resin placement techniques on the microleakage of two self-etching dentin-bonding agents. Am J Dent 2001;14:132-6.

29. Cardoso PE, Placido E, Francci CE, Perdigao J. Microleakage of class $\mathrm{V}$ resin-based composite restorations using five simplified adhesive systems. Am J Dent 1999;12(6):291-4 